Michal Frivaldsky - Jan Morgos*

\title{
DC-DC CONVERTER DESIGN ISSUES FOR HIGH-EFFICIENT DC MICROGRID
}

In this article, the electrical properties, as well as the economic aspects of the modular and non-modular solution of the DC-DC photovoltaic converter for DC microgrid subsystem, are described. Principally a theoretical overview of the circuit configuration for the selected DC-DC stage of the DC microgrid system is shown. It is dealt with the comparison of the one non-modular high - voltage SiC-based dual - interleaved converter operating at the low switching frequency and with modular low voltage GaN-based DC-DC converters operating at high switching frequencies. The main focus is given to the research of the dependency that arises from the different module count, overall efficiency, costs, and power density (system volume). High efficiency, reduced overall volume, and maximum power density are important factors within modern and progressive solar systems. It is assumed that with the increase of switching frequency within the modular system the volume reduction of the passive components will be highly demanded, thus PCB dimensions and overall volume can be reduced. This dependency is investigated, while the total volume of the non-modular system is a unit of the measure. For these purposes, the design of variant solution was done, and consequently mutually compared in the way of simulations and experimental measurements.

Keywords: modular system, efficiency, cost, GaN, SiC

\section{Introduction}

Humankind has come to a stage where it is evident that the climatic changes of our planet are so extensive that our way of life cannot be sustained for a long time. The measures to reduce the impact on the climate changes also include a change of the process of the use of primary energy source - fossil fuels. Nowadays, many attempts have been done in order to shift from fossil fuels to clean or renewable primary energy sources (photovoltaic systems, wind and water turbines, energy hubs and smart-grids) [1-4].

Strong development of the green and alternative or renewable energy systems (RES) has been intensively investigated for almost a decade. In most of the European countries, it has occurred since 2008, when the European Union's effort to introduce mandatory RES shares in the energy sector for all EU Member States culminated [5].

The electricity system and the overall energy sector are currently under the influence of significant changes. On the one hand, there is increasing pressure on new, mostly small, electricity sources. Whether it is the use of solar energy or biomass (biogas, the conversion of bio-waste to energy, etc.), but also other technologies. At the same time, however, there is a gradual change in consumer models. Global requirements on the energy consumption continuously grow. One of the ways how to provide smooth and reliable energy distribution lies also in the utilization of the very highly efficient systems with considerable power densities [6,7].

From this point of view, it is therefore important to develop hardware and software solutions that would provide optimal energy management between the supply grid and consumer (household) and also between individual components of the energy system of modern household (primary sources of energy, accumulation of energy, and energy distribution to the consumers). Moreover, if such an intelligent power hub could co-operate with other nodes in its vicinity (narrower or wider), the technical conditions would be created for the massive use of electric cars and renewable sources without negative impact on the power distribution grid $[8,9]$.

In this paper, a proposal for the intelligent power hub is given, while the more detailed focus is given on the construction block of the power converter system. It deals with DC-DC photovoltaic converter, which can be designed in several ways [10]. In this paper, the modular and non-modular solution of the buck-boost bi-directional converter is considered, while the focus is given on the mutual comparison of the efficiency, cost and power density for the target application.

\section{The concept of an energy hub for DC microgrid}

Due to increased use of the portion of solar energy and other renewable energy sources, it is necessary to consider with intelligent energy hubs within DC-microgrids of the households. There is also the visible rise of the use of electric vehicles that also influences the concept of smart energy hubs. Such hub has to optimally manage energy flow between individual energy storage systems and energy sources/consumers. Also, there is a need to gain information about energy consumption and state of the charge of energy storage systems. There is the possibility of an Internet connection and possibility to control and monitor system from anywhere with the use of IoT systems.

- A principal block diagram of the concept of perspective energy hub is shown in Figure 1. The system consists of photovoltaic cells,

\footnotetext{
* Michal Frivaldsky, Jan Morgos

Department of Mechatronics and Electronics, University of Zilina, Slovakia

E-mail: michal.frivaldsky@fel.uniza.sk
} 


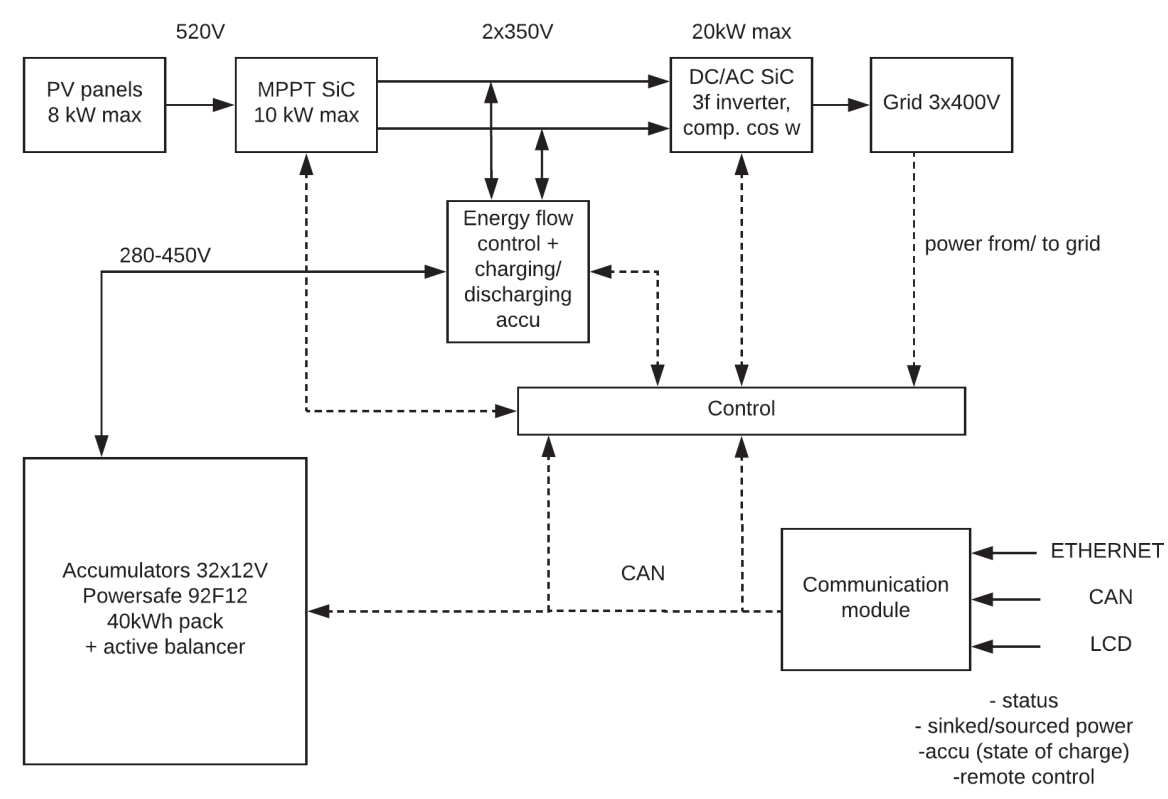

Figure 1 Block diagram of the proposed energy

Table 1 Table of input parameters for the proposed system

\begin{tabular}{lc}
\hline Parameter & Value \\
\hline Output voltage range from PV panels & $500-560 \mathrm{~V} \mathrm{DC}$ \\
Output power from PV panels & $10 \mathrm{~kW}$ peak \\
Output voltage (DC bus voltage) & $600 \mathrm{~V} \mathrm{DC}$ \\
Output MPPT converter power & $10 \mathrm{~kW}$ peak \\
\hline
\end{tabular}

- Maximum power point tracking (MPPT)DC-DC converter,

- energy management block,

- three-phase inverter,

- energy storage block, a

- bidirectional DC-DC converter for charging/discharging of the energy storage system,

- control and communicating block.

In this paper, the attention is given to the MPPT DC-DC converter block, while topological optimization is realized in the way of achieving the highest possible efficiency, lowest possible costs and dimensions for defined input-output conditions. Comparison of the modular and non-modular concept is described.

\section{The non-modular and modular concept of DC-DC MPPT converter}

In this part topological analysis of MPPT DC-DC converter is given. Since the design of MPPT converter has to be adjusted to the target application (exact number of cells/modules) the input/ output parameters are exactly defined, and the proposed solutions are designed considering required voltages and currents (Table 1).

Principal block diagrams for non-modular and modular solutions are shown in Figure 2. Input voltage for the non-modular system is directly connected to the input of the converter at full level (serially connected PV strings). For the modular system, the input voltage is divided between the serial connection of the modular converter blocks. The output voltage for both concepts shall be $600 \mathrm{~V}$, thus for the non-modular solution the output is single, while the modular solution is defined again by the serial connection of the outputs of the individual converters in order to generate an output voltage of $600 \mathrm{~V}$.

Main circuit topology of the non-modular solution is based on the non-isolated DC-DC interleaved synchronous boost converter with SiC-based transistors and diodes. A circuit schematic of this converter is shown in Figure 3. Due to interleaved topology, it is possible to achieve low current and voltage stress for the semiconductor components, and lower voltage and current ripple at the output filtering capacitor. Another benefit is also reduction of the volume of boost inductor and improved thermal performance of the total system.

Individual building blocks of the modular system, shown on Figure 4, are based on the GaN technology of the semiconductor components. Due to dividing the power and voltages to separate individual blocks, it is possible to increase switching frequency several times. One DC-DC converter thus operates with lower voltage and power (thus low voltage - high current, high frequency switching devices can be used). Such approach might reduce dimensions of used components (magnetic components, capacitors, PCB). Thanks to lower dimensions it is possible to design converters with smaller $\mathrm{PCB}$, while the volume of a complex modular system would be smaller compared to the nonmodular system. 

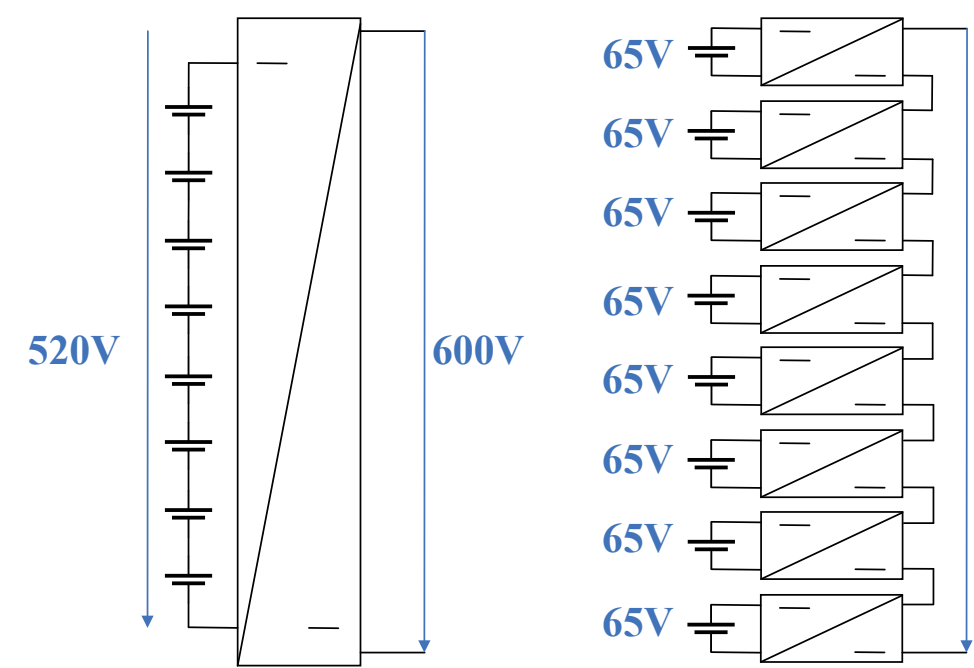

Figure 2 Block diagram for a non-modular (left) and modular solution (right) of DC-DC MPPT converter

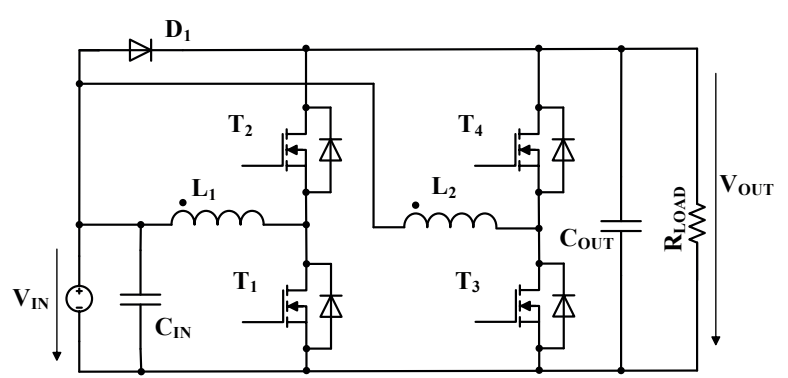

Figure 3 An electrical schematic of non-modular DC-DC converter utilizing SiC technology of semiconductor devices

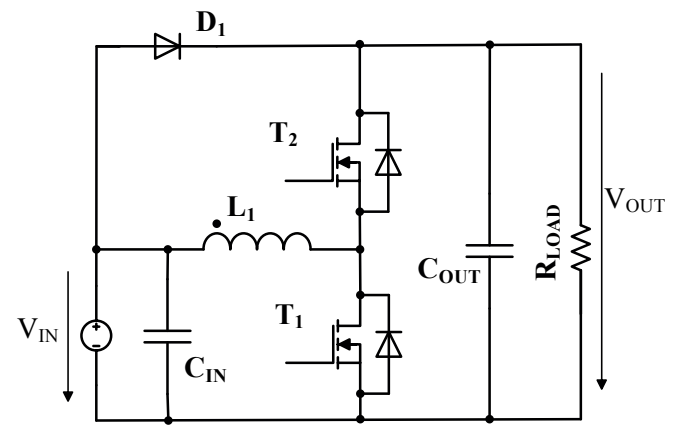

Figure 4 An electrical schematic of modular DC-DC converter utilizing GaN technology of semiconductor devices
Next Equations (1) - (3) have been used for the determination of the main circuit components that are affecting the converter volume. The input and output variables have been modified, i.e. input/output voltage and duty cycle, when modular and the nonmodular concept was considered. The percentage of the ripple of the output variables was the same even the numbers of the modules vary.

$$
L[H]=\frac{V_{\text {in }} *\left(V_{\text {out }}-V_{\text {in }}\right)}{\Delta i_{L} * I_{\text {out } \text { max }} * f_{\text {sw }} * V_{\text {out }}},
$$

where:

$\mathrm{U}_{\text {in }}$ - input converter voltage [V],

$\mathrm{U}_{\text {out }}$ - output converter voltage [V],

$\mathrm{f}_{\text {sw }}$ - switching frequency $[\mathrm{Hz}]$,

$\Delta \mathrm{i}_{\mathrm{L}}$ - ripple of inductor current [\%],

$\mathrm{I}_{\text {out_max }}$ - maximum output current $[\mathrm{A}]$.

$D[\%]=1-\frac{V_{\text {in } \min }}{V_{\text {out }}}$,

where:

$\mathrm{U}_{\text {in }}$ - minimum input converter voltage [V],

$\mathrm{U}_{\text {out }}$ - output converter voltage [V].

$C_{\text {out }}[F]=\frac{I_{\text {out } \max } * D}{f_{\text {sw }} * \Delta V_{\text {out }}}$,

where:

$I_{\text {out } \max }$ - maximum output current [A],

D - duty cycle [\%], $\mathrm{f}_{\mathrm{sw}}$ - switching frequency $[\mathrm{kHz}]$,

$\Delta \mathrm{U}_{\text {out }}$ - ripple of output voltage [\%],

$\mathrm{U}_{\text {out }}$ - output voltage [V].

Figure 5 and Figure 6 show 3D dependency of the values of boost inductor $\mathrm{L}$ and filter capacitor $\mathrm{C}_{\text {OUT }}$ when the number of modules and switching frequency vary, while input/output parameters are relevant for individual module count. It must be noted, that the interpretation considers with one component, when the computation was realized. Thus for whole module solution, the result must be multiplied by the relevant number of the considered modules. Table 2 shows input/output parameters that have been included within calculation of the $\mathrm{L}$ and $\mathrm{C}_{\text {out }}$. At this point the need for the semiconductor devices is considered. It is seen, that for the situation when 2 up to 4 stages are considered there is a necessity to use high-voltage GaN transistors (650 $\mathrm{V})$, while the target price and investments for the design of the proposed system will markedly increase. When a higher number of modules (over 4) is considered, the input and output voltage will be divided by the DC-DC stages, thus transistors with lower breakdown voltage $U_{D S}$ can be used $(100 \mathrm{~V})$. As a satisfaction, the transistor costs will also be reduced compared to the high-voltage solution. 


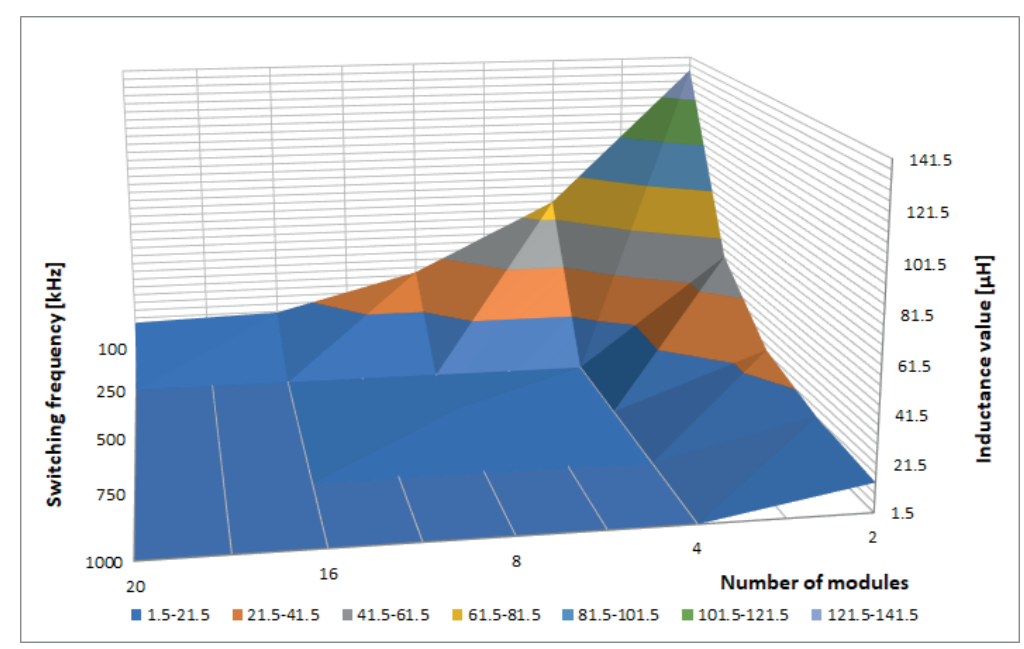

Figure $53 D$ dependency of the inductance $L$ value on number of modules and switching frequency

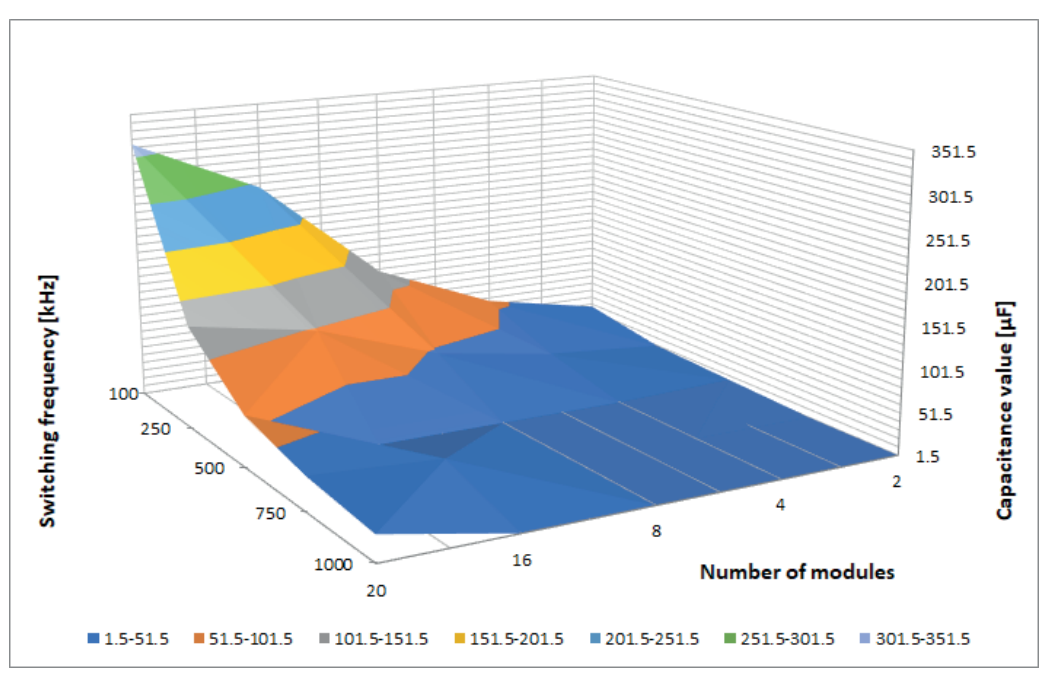

Figure $63 D$ dependency of the capacitance $C_{\text {out }}$ value on the number of modules and switching frequency

Table 2 Table of input parameters of the proposed system

\begin{tabular}{ccccccc}
\hline Module count & Input voltage & Output voltage & Output power & $\mathrm{V}_{\mathrm{DS}}[\mathrm{V}]$ & $\mathrm{I}_{\mathrm{D}}[\mathrm{A}]$ & $\mathrm{R}_{\mathrm{DSon}}[\mathrm{m} \Omega]$ \\
\hline 1 (nonmodular) & 520 & 600 & 10000 & $1200(\mathrm{SiC})$ & 30 & 75 \\
2 & 260 & 300 & 5000 & $650(\mathrm{GaN})$ & 30 & 55 \\
4 & 130 & 150 & 2500 & $650(\mathrm{GaN})$ & 30 & 30 \\
8 & 65 & 75 & 1250 & $100(\mathrm{GaN})$ & $45(\mathrm{GaN})$ & 15 \\
16 & 32.5 & 37.5 & 625 & $100(\mathrm{GaN})$ & 45 & 15 \\
\hline
\end{tabular}

4. Comparison of the properties of the modular and non-modular solution - costs, efficiency, volume, performance

At this place, the economic performance together with efficiency and power density calculation are given. Initially, Table 3 shows an expert estimation of the investments necessary for the design of proposed solutions of the MPPT DC-DC converter. The estimation considers with the whole bill of materials of electronic parts (power semiconductor components, drivers, magnetic components, passive components and PCB), while standard distribution network was considered. It is seen, that the initial costs of the non-modular DC-DC interleaved converter based on the $\mathrm{SiC}$ technology is comparable to the initial costs that are relevant for almost up to 16-stage modular DC-DC converter. Figure 7 shows graphical interpretation of the costs related in dependency on the number of modules, while switching frequency is also variable. From Figure 7 can be seen, that with the increase of the switching frequency the costs are decreasing, what is related to the fact, that smaller reactive components can be used within 
Table 3 Table of build costs of the proposed system

\begin{tabular}{cccccccc}
\hline & T & Cin & Cout & L & PCB & oths & total \\
\hline non modular $(50 \mathrm{kHz})$ & 20 & 12 & 40 & 150 & 490 & 40 \\
2 modules $(100 \mathrm{kHz})$ & 65 & 11 & 14 & 22 & 320 & 20 \\
4 modules $(100 \mathrm{kHz})$ & 130 & 22 & 26 & 56 & 275 & 22 & $532 €$ \\
8 modules $(100 \mathrm{kHz})$ & 83 & 28 & 37 & 80 & 210 & 27 & $438 €$ \\
16 modules $(100 \mathrm{kHz})$ & 167 & 38 & 180 & 73 & 320 & 40 \\
20 modules $(100 \mathrm{kHz})$ & 209 & 65 & 210 & 100 & 280 & 50 \\
\hline
\end{tabular}

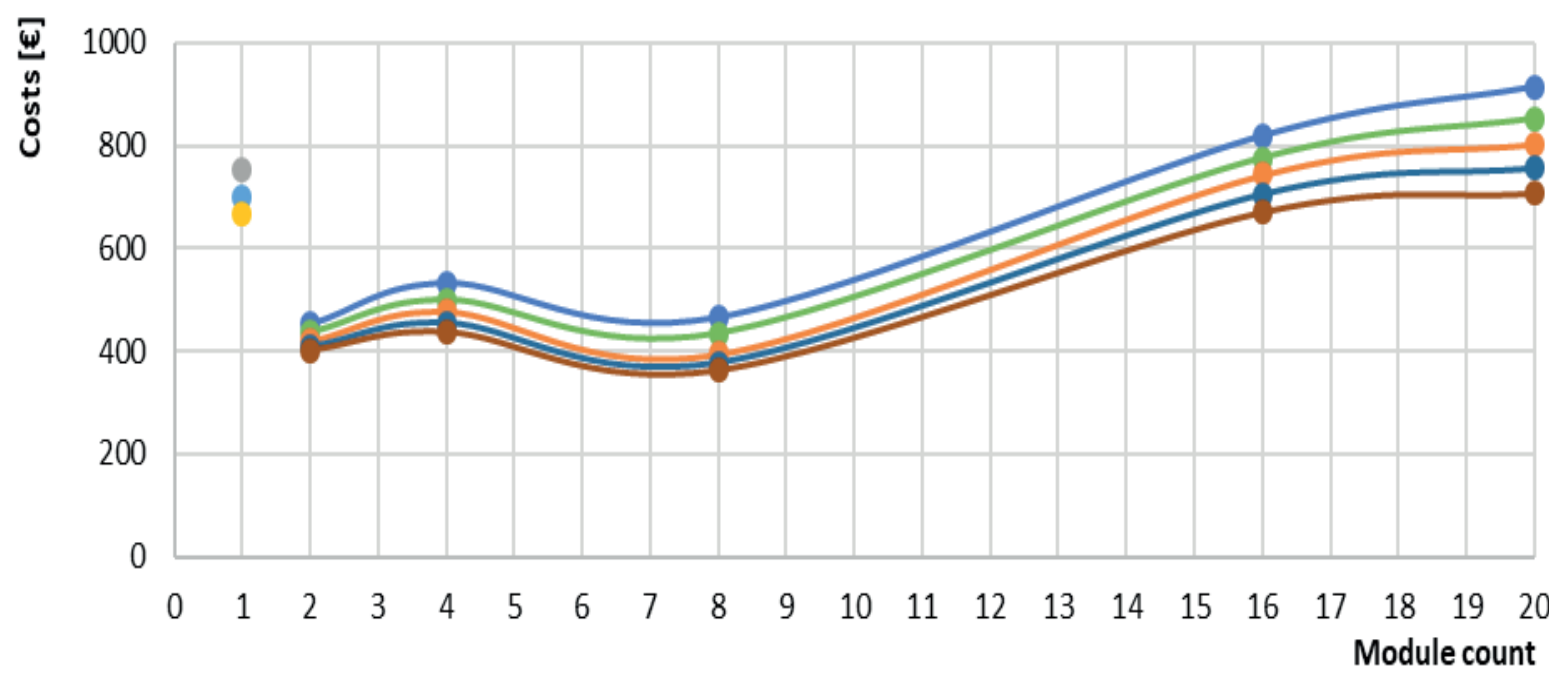

\section{- Non-modular $50 \mathrm{kHz}$ \\ - Non-modular $75 \mathrm{kHz}$ \\ $\rightarrow$ Non-modular $100 \mathrm{kHz} \rightarrow$ Modular $100 \mathrm{kHz}$ \\ $\rightarrow-$ Modular $250 \mathrm{kHz}$ \\ $\rightarrow-$ Modular $500 \mathrm{kHz}$ \\ Modular $750 \mathrm{kHz}$ \\ $\rightarrow$ Modular $1000 \mathrm{kHz}$}

Figure 7 Comparison of costs of non-modular and modular solution in dependency on switching frequency and number of modules

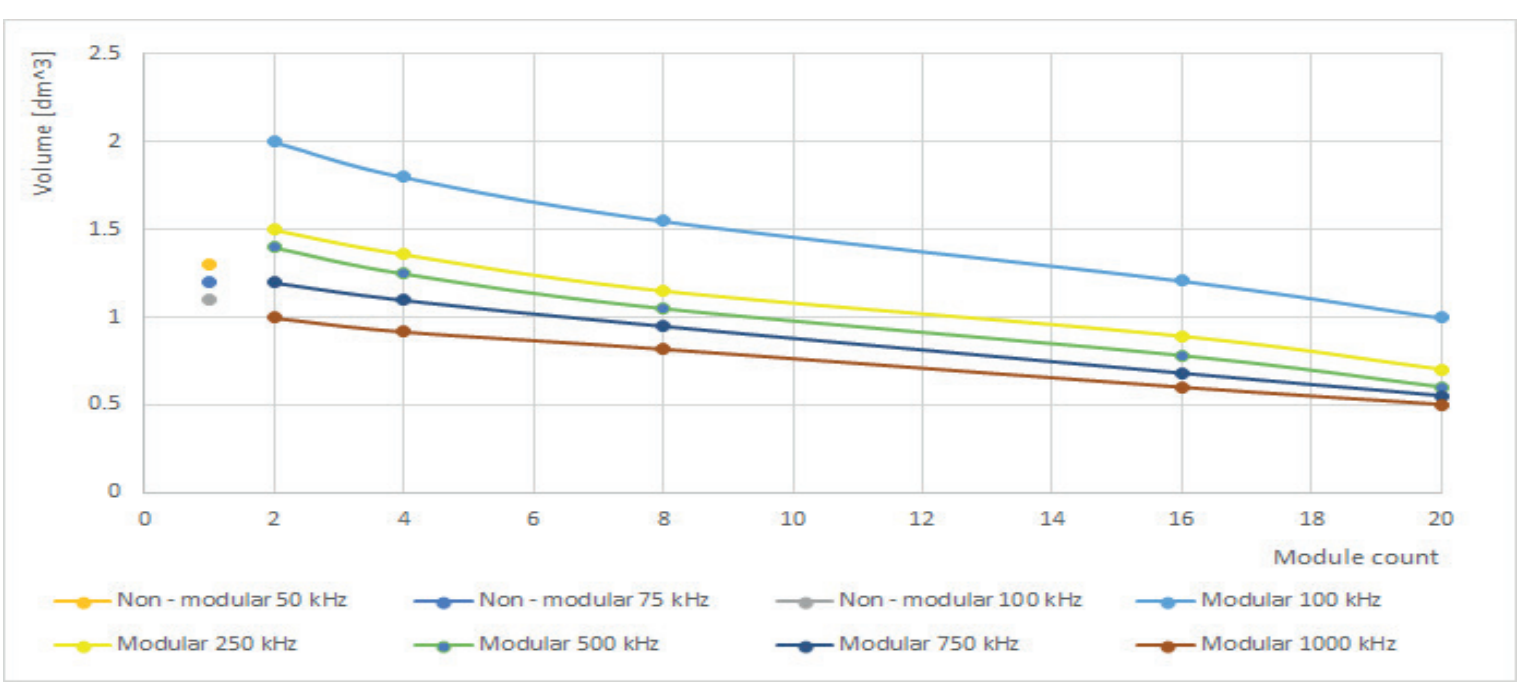

Figure 8 Comparison of build volumes of modular solutions for different switching frequencies and for different module count

the converter's main circuit. Also, the drop of the cost is visible around the 8 count of the modules. It is caused due to fact, that the transistor with lower drain-source voltage can be used within main circuit, thus the price for the semiconductor reduces.

Considering volume (power density), non-modular solution exhibits performance that is dependent on the switching frequency and input/output parameters that are limited due to power delivery and semiconductor performance. For high power levels, it is expected to operate at lower frequencies in order to prevent from unwanted negative impacts (safety reasons, EMC etc.), while robust semiconductors must be used (IGBT, SiC MOSFETS). On the other hand, modular solution enables to split individual 


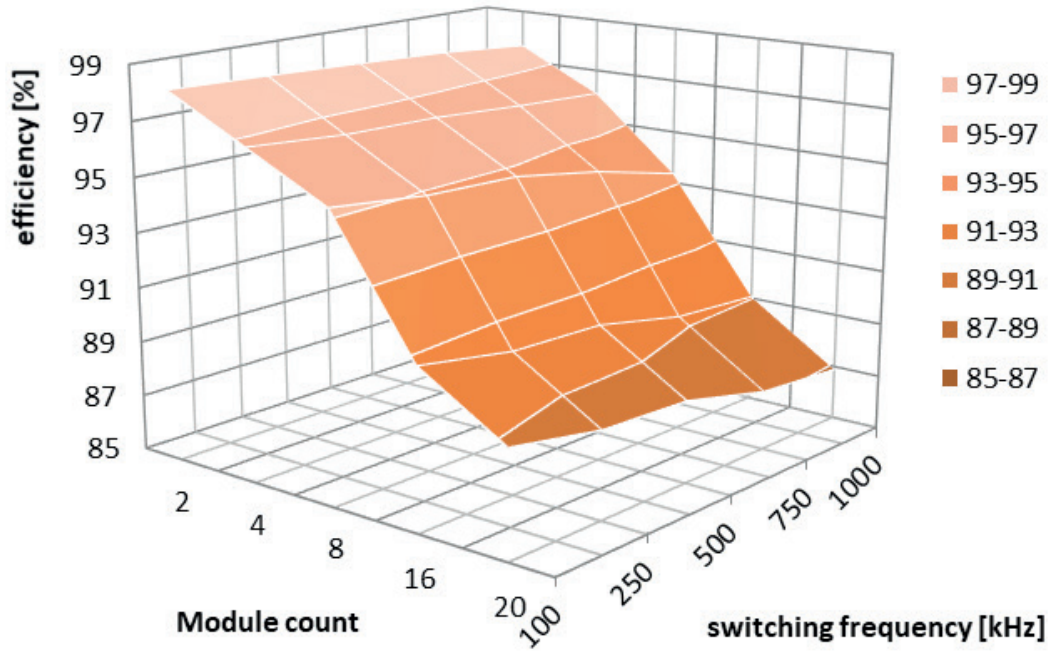

Figure 9 Comparison of efficiencies of modular solutions for different switching frequencies and for different module count

Table 4 Table of input/output voltage and current ripples for non-modular and modular solutions

\begin{tabular}{ccccc}
\hline Module count & Input voltage ripple & Input current ripple & Output voltage ripple & Output current ripple \\
\hline $1(\mathrm{SiC})$ & $0.04 \%$ & $36.5 \%$ & $3.96 \%$ & $3.88 \%$ \\
$2(\mathrm{GaN})$ & $0.02 \%$ & $5.31 \%$ & $0.33 \%$ & $0.35 \%$ \\
$4(\mathrm{GaN})$ & $0.03 \%$ & $5.63 \%$ & $0.21 \%$ & $0.22 \%$ \\
$8(\mathrm{GaN})$ & $0.08 \%$ & $6.37 \%$ & $0.21 \%$ & $0.21 \%$ \\
\hline
\end{tabular}

converters to lower input/output operating levels. Therefore the high-switching frequency operation is easily to utilize. With this increase, the volume of the passive components can be visibly reduced. Moreover, when $\mathrm{GaN}$ technology is considered, also the volume of the semiconductors minimizes. GaN-based converter system has a big advantage if very small volume and weight are required. Typical examples are mobile systems, compact converter systems or electromobiles e.g. Figure 8 shows dependency of the volume on the number of modules, while switching frequency is also variable parameter. It is seen that with the increase of switching frequency the total volume of the modular converter system can be reduced below the volume of the non-modular solution, whereby this is valid from $250 \mathrm{kHz}$ of switching frequency and above 5 numbers of the modules.

Graphical comparison of overall efficiency of the modular solution in dependency on module count and switching frequency is shown in Figure 9. Individual results have been received from the PSpice simulations, while high-precision models of semiconductors and passive components have been utilized. Non-modular solution was evaluated for the $75 \mathrm{kHz}$, whereby the efficiency was $98.5 \%$ and is not plotted. For the calculation of efficiency of modular solution, Equations (4) and (5) were used. It is obvious that with the increasing module count, there is a decrease of overall efficiency of the modular solution. Also the increase of switching frequency causes the decrease of overall efficiency due to increase of switching and conduction losses.

$\eta=\frac{P_{\text {out }}}{P_{\text {in }}}$
The efficiency of modular system can be calculated as:

$\eta^{*}=\frac{n * P_{\text {out }}^{*}}{n * P_{\text {in }}^{*}}=\frac{P_{\text {out }}^{*}}{P_{\text {in }}^{*}}$,

where:

$\mathrm{n}$ - module count,

$\eta$ - efficiency,

Pin - input power,

Pout - output power.

From Figure 9 is seen that the main disadvantage of the increase of module count is efficiency decrease. Therefore optimizations within main circuit must be done in order to reduce the most of conduction losses (due to higher currents). For this reason there shall be compromise between previously mentioned abilities (power density and costs) and target efficiency. Almost 8 module systems are able to operate at relatively very high efficiency $95 \%$ and high switching frequency $(500 \mathrm{kHz})$. In this way the volume can be decreased compared to non-modular solution (Figure 8) while investments can be reduced by more than $40 \%$ of non-modular costs.

Final comparison of presented design approaches was realized through investigation of the input/output current/voltage ripple. From Table 4 is seen, that visible reduction can be achieved with modular solution thus improving the distortion of input/ output waveforms. This is beneficial for sensitive loads. 


\section{Conclusion}

In this article differences between modular and non-modular solutions for photovoltaic MPPT converters have been described. Initially the main circuit of the individual solution have been shown for selected application. Main focus was given on the performance from cost, volume and efficiency point of view. It was shown, that modular solution enables more design flexibility whereby mentioned parameters can be modified to the target application. Investigation was performed in parametric ways, and individual variables were described in dependency on the operating conditions of presented solutions.

As regards the evaluation of the financial charges for individual system constructions, the modulation rate is not directly increasing investments what was related to the different component selection. The modular cost can be lower compared to non-modular up to a certain count of the modules (up to 16). Due to the high spin rate, the system can be constructed from a small amount of modulation, which reduces the total volume of the system. The modular system provides a smaller dimension to the number of modules 10 compared to a non-modular system but increases the number of individual building blocks in the modular system directly to the overall efficiency of the system.

Next steps in our research will be: design, practical realization of the physical samples and testing of the proposed modular system.

\section{Acknowledgements}

The authors wish to thank Slovak grant agency APVV for the project no. 0396-15 - Research of perspective high-frequency converter systems with GaN technology. Authors also would like to thank for the support from the national grant agency VEGA for the project no. 1/0547/18 - Research of possibilities for system optimization of WET technology.

\section{References}

[1] SEDO, J., KASCAK, S. Design of output LCL filter and control of single-phase inverter for grid-connected system. Electrical Engineering - Archiv fur Elektrotechnik [online]. 2017, 99(4), p. 1217-1232. ISSN 0948-7921/eISSN 1432-0487. Available from: https://doi.org/10.1007/s00202-017-0617-0

[2] AIELLO, G., et al. A high efficiency interleaved PFC front-end converter for EV battery charger. Communications - Scientific Letters of the University of Zilina [online]. 2018, 20(1), p. 86-92. ISSN 1335-4205/eISSN 2585-7878. Available from: http://komunikacie. uniza.sk/index.php/communications/article/view/52

[3] GALAD, MARTIN, et al. Analysis of state of charge estimation methods for smart grid with VRLA batteries. Electrical Engineering - Archiv fur Elektrotechnik [online]. 2017, 99(4), p. 1233-1244. ISSN 0948-7921/eISSN 1432-0487. Available from: https://doi. org/10.1007/s00202-017-0618-z

[4] NOBILE, G., et al. Multi-criteria experimental comparison of batteries circuital models for automotive applications. Communications - Scientific Letters of the University of Zilina [online]. 2018, 20(1), p. 97 - 104. ISSN 1335-4205/eISSN 2585-7878. Available from: http://komunikacie.uniza.sk/index.php/communications/article/view/54

[5] STEPINS, D., HUANG, J. Optimization of modulation waveforms for improved EMI attenuation in switching frequency modulated power converters. Advances in electrical and electronic engineering [online]. 2015, 13(1), p. 10-21. ISSN 1804-3119/eISSN 1336-1376. Available from: https://doi.org/ 10.15598/aeee.v13i1.1142

[6] GALAD, M., SEDO, J., SPANIK, P. Developing of stand-alone power system simulation model. International review of automatic control (IREACO) [online]. 2014, 7(5), p. 500-505. ISSN 1974-6059/eISSN 2533-2260. Available from: https://doi.org/10.15866/ ireaco.v7i5.3867

[7] CHLEBIS, P., et al. The system of fast charging station for electric vehicles with minimal impact on the electrical grid. Advances in electrical and electronic engineering [online]. 2016, 14(2), p. 89-94. ISSN 1804-3119/eISSN 1336-1376. Available from: https://doi. org/10.15598/aeee.v14i2.1318

[8] TVRDON, M., CHLEBIS, P., HROMJAK, M. Design of power converters for renewable energy sources and electric vehicles charging. Advances in electrical and electronic engineering [online]. 2013, 11(3), p. 204-209. ISSN 1804-3119/eISSN 1336-1376. Available from: https://doi.org/10.15598/aeee.v11i3.795

[9] XUE, F., YU, R., HUANG, A. Q. A 98.3\% efficient GaN isolated bidirectional DC-DC converter for DC microgrid energy storage system applications. IEEE Transactions on Industrial Electronics [online]. 2017, 64(11), p. 9094-9103. ISSN 0278-0046/eISSN 15579948. Available from: https://doi.org/10.1109/TIE.2017.2686307

[10] GALAD, M., SPANIK, P. Design of photovoltaic solar cell model for stand-alone renewable system. In 10th international conference ELEKTRO 2014: proceedings. Slovakia, 2014. ISBN 978-1-4799-3720-2, CD-ROM, p. 285-288. 